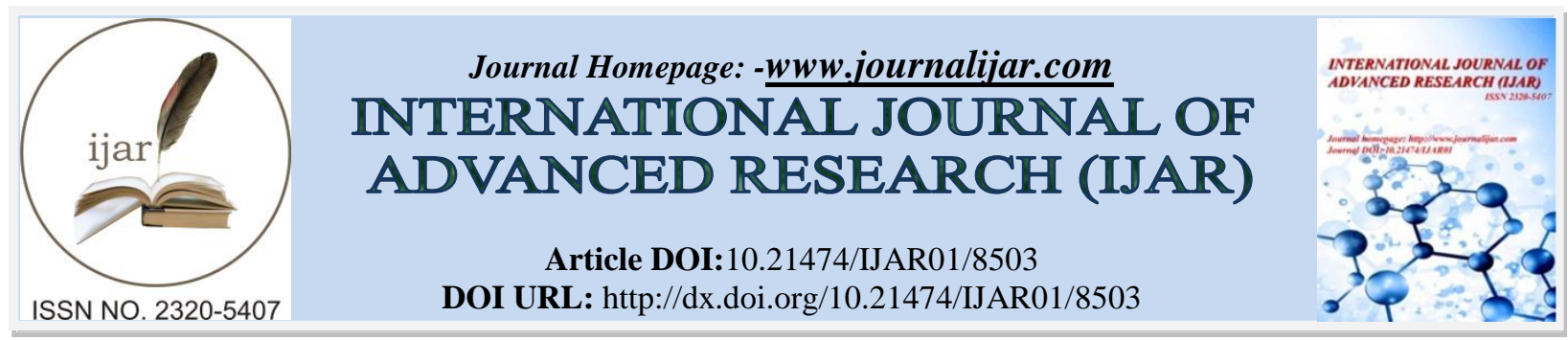

RESEARCH ARTICLE

\title{
AEROBIC BACTERIOLOGICAL PROFILE OF SURGICAL SITE INFECTIONS WITH ANTIBIOGRAM.
}

Sowmya Modugula, P. Ratna Kumari and R. Lakshmi Kumari.

Department of Microbiology, Siddhartha Medical College, Vijayawada-520008.

\section{Manuscript Info}

Manuscript History

Received: 05 December 2018

Final Accepted: 07 January 2019

Published: February 2019

Key words:-

Infection, Isolates,Surgical Site,clinical.

\begin{abstract}
The present study was done on 236 clinically suspected pus samples from patients who underwent surgery between Jan 2017 to June 2017 from Obstetrics and gynecology, General surgery and Orthopedic departments in Government General Hospital,Vijayawada.This study was done to know the incidence of surgical site infections and the prevalence of aerobic bacterial pathogens along with their antibiogram. Surgical site infections (SSI) are the second most common nosocomial infections and have adverse impact on patients. Isolation and identification of the organisms was done by gram stains and culture growth. Antimicrobial susceptibility testing was performed by KirbyBauer disc diffusion method and results were interpreted as per Clinical and Laboratory Standards Institute(CLSI) guidelines. Out of 236 clinically suspected pus samples received in the microbiology laboratory, Siddhartha Medical College, 137 (58\%) were culture positive and 99(41.9\%) were culture negative. The infection was found to be higher in female patients in age group 21-30yrs than in male patients. The most commonly isolated pathogens were Staphylococcus aureus 38(27.7\%) followed by Klebsiella species 29(21.1\%)and Escherichia coli 26(18.9\%). Antimicrobial profile of gram positive isolates revealed highest sensitivity to amikacin (68.4\%), followed by linezolid(60.5\%), whereas gram negative isolates showed most sensitivity to amikacin (58.6\%) and piperacillin tazobactum $(44.8 \%)$.SSI are responsible for increasing the treatment cost, length of hospital stay and significant morbidity and mortality.Hence proper, formulation of infection control policies, hand hygiene techniques and optimal preoperative, intraoperative and postoperative patient care can be implemented to reduce the incidence of surgical site infections.
\end{abstract}

Copy Right, IJAR, 2019,. All rights reserved.

\section{Introduction:-}

Surgical site infections (SSI) are one of the most important cause of healthcare-associated infections(HCAIs) which have adverse impact on patients. They are responsible for increasing the treatment cost, length of hospital stay and significant morbidity and mortality.The majority of SSI is caused by the native flora of the patient's skin, mucous membranes, or hollow viscera. SSI can be caused when skin is incised, underlying tissue is exposed to overlying endogenous flora. It is also caused by the organisms present in the hospital environment that are introduced to the 
patient by medical procedures.It is important to recognise that SSIs can range from a relatively trivial wound discharge with no other complications to a life-threatening condition. Identification of SSI involves interpretation of clinical and laboratory findings rather than microbiological evidence alone. The majority of SSIs become apparent within 30 days of an operative procedure. However, where a prosthetic implant is used, SSIs affecting the deeper tissues may occur several months after the operation. The development of an SSI depends on contamination of the wound site at the end of a surgical procedure and specifically relates to thepathogenicity and inoculum of microorganisms present, balanced against the host's immune response. Risk factors other than microbiology can be due to systemic factors affecting the patient's healing response, local wound characteristics, or operative characteristics. . In addition irrational use of broad spectrum antibiotics and resulting anti microbial resistance(AMR) has further deteriorated the condition. The problem gets more complicated in developing countries due to poor infection control practices, overcrowded hospitals and inappropriate use of antimicrobials.

\section{Methods:-}

The present study was conducted in the Department of Microbiology, Government General Hospital, Vijayawada, where patients who underwent surgery between Jan 2017 to June 2017 from Obstetrics and Gynecology, General surgery and Orthopedic department.All the 236 pus samples from clinically suspected SSIs were processed in the microbiology laboratory.

SSIs were diagnosed according to the guidelines of the Centers for Disease Control and Prevention. The CDC criteria were used to define the type of surgical wound using the wound contamination class system.Surgical sites were considered to be infected according to the set of clinical criteria recommended by the surgical infection task force.

Swabs from deep part of the wound or pus were taken from the infected surgical sites using two sterile cotton swabs, and were subjected to gram staining,biochemical reactions and cultured aerobically.Care was taken

not to touch the surrounding tissues to prevent contamination of the swab from endogenous resident flora.Bacterial pathogens were identified and tested for antimicrobial susceptibility by Kirby-Bauer disc

diffusion methods and results were interpreted as per Clinical and Laboratory Standards Institute (CLSI)guidelines 2017.

\section{Results:-}

In the present study, out of 236 samples,121(51.27\%) specimens were from male patients and $115(48.72 \%)$ were from female patients. Among 137 culture positive cases, 70(51.09\%) were from specimens of female patients and $67(48.90 \%)$ were from specimens of male patients. The infection $(58 \%)$ was found to be higher in female patients in age group 21-30yrs(44.2\%).(Fig:1)

Out of 236 pus samples from clinically suspected SSIs which were processed in the microbiology laboratory,137(58\%)were culture positive while 99(41.9\%) had no growth.(Fig:2).Out of 137 bacterial isolates 83(60.5\%) were Gram Negative Bacilli(GNB) and 54(39.4\%)were Gram Positive Cocci(GPC). Staphylococcus aureus was $38(27.7 \%$ ) followed by Klebsiella species $29(21.1 \%)$,Escherichia.Coli $26(18.9 \%)$ and pseudomonas 19(13.8\%).(Table 1).Antimicrobial profile of gram positive isolates revealed highest sensitivity to amikacin(68.4\%),followed by linezolid(60.5\%),(Fig:3), whereas gram negative isolates showed highest sensitivity to amikacin(58.6\%) followed by piperacillintazobactum(44.8\%).( Fig:4).

\section{Discussion:-}

In the field of surgery wound infections have been a problem for a long time which remains as one of the most common nosocomial infection in surgically treated patients.During postoperative period an infected wound complicates and results in prolonged stay in the hospital and delayed recovery.In the present study, an attempt has been made to know the various bacterial pathogens responsible for SSIs and their antibacterial susceptibility pattern.. The most common organism isolated was staphylococcus aureus 38(27.7\%)which is nearer to the study conducted by Bastola et al.,(21.8\%) and Siddiqui et al(22.03\%). Gram negative isolates comprised of $60.5 \%$ out of which Klebsiella species(21.1\%) was the commonest gram negative bacteria isolates followed by E.coli(18.9\%) and pseudomonas(13.8\%).Some of the studies have reported pseudomonas as the most frequent isolate in SSI(kokate et al.,)where as in this study it remains as a fourth most isolated organism. The present study also reveals that amkacin $(53.2 \%)$ was the most effective drug against gram positive and gram negativebacteria. 
In conclusion, SSI causes considerable morbidity among surgical patients.Appropriate active surveillance and infection control measures such as proper hand hygiene techniques should be introduced during preoperative, intraoperative, and postoperative care to reduce the incidence of surgical site infection.Thus, every hospital needs to organize its infection control program.Irrational use of antibiotics should be stopped. The information obtained from this study allows abetter understanding of the microbial etiology of SSIs in our hospital.Inspite of modern surgical and sterilization techniques and the use of prophylactic antimicrobials, SSIs still continue to be an important clinical challenge.

\section{Acknowledgement:-}

I am thank full to all the doctors, technical staff of Microbiology Department, Government General Hospital,Siddhartha Medical College,Vijayawada who cooperated us in carrying out this research work.

Fig 1:-Sex and Age wise distribution

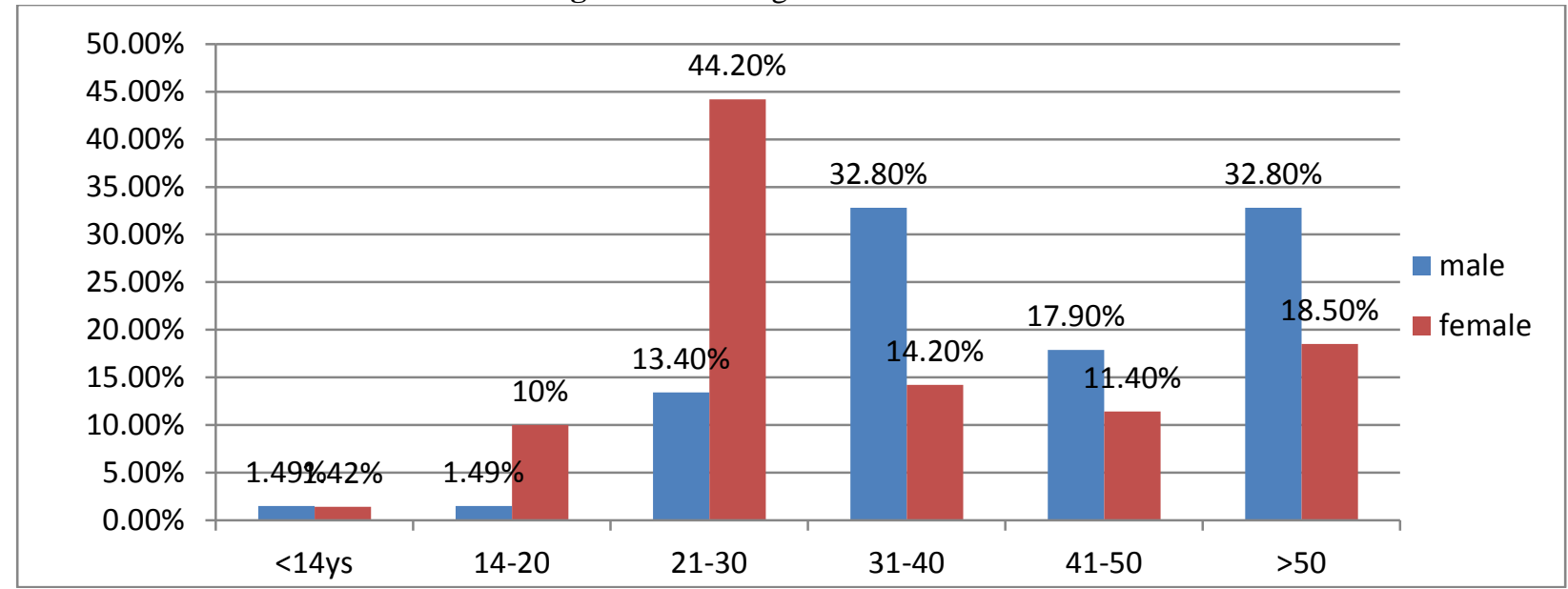

Fig 2:-Total number of sample

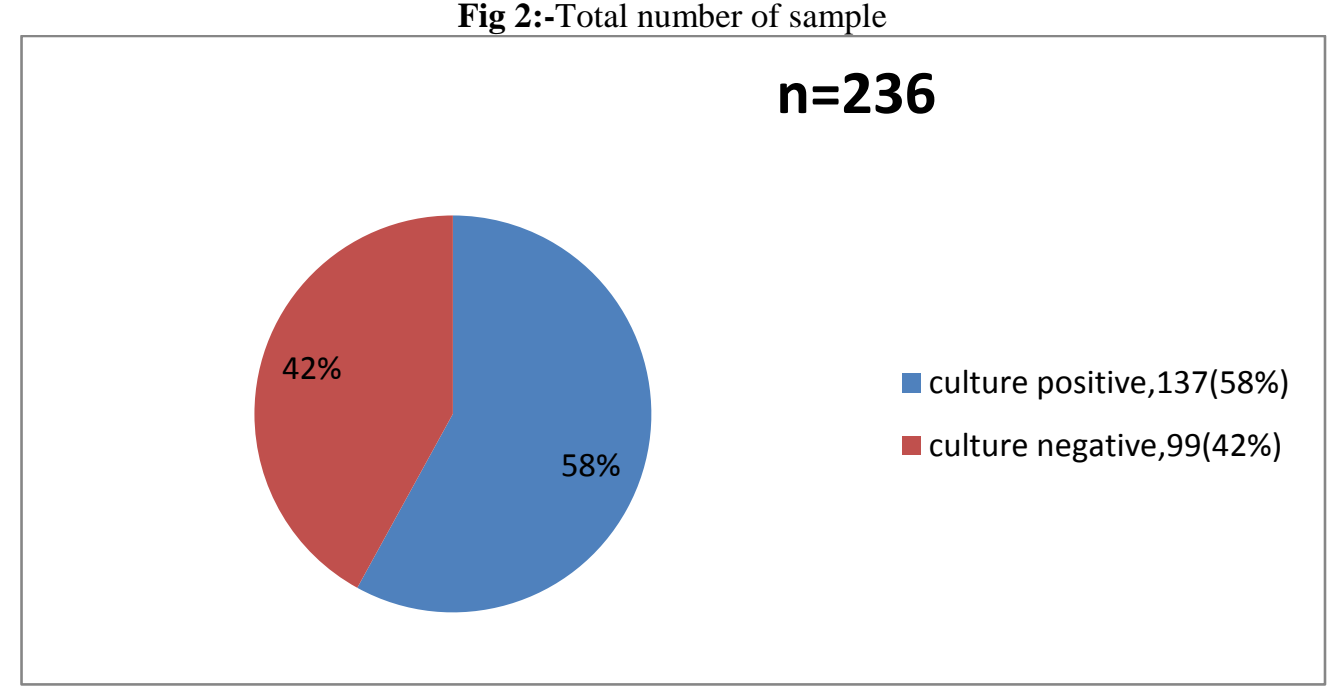


Table 1:-Organisms isolated in pus culture $(\mathrm{n}=137)$

\begin{tabular}{|l|l|l|l|}
\hline S.NO & Organism Isolated & Number of isolates $(\mathrm{n}=137)$ & $\%$ \\
\hline 1 & Staphylococcus aureus & 38 & 27.7 \\
\hline 2 & Klebsiella species & 29 & 21.1 \\
\hline 3 & Escherichia Coli & 26 & 18.9 \\
\hline 4 & Pseudomonas & 19 & 13.8 \\
\hline 5 & CONS & 16 & 11.6 \\
\hline 6 & Proteus & 6 & 4.37 \\
\hline 7 & Enterobacter & 3 & 2.18 \\
\hline
\end{tabular}

Fig 3:-Antibiotic sensitivity pattern of staphylococcus aureus

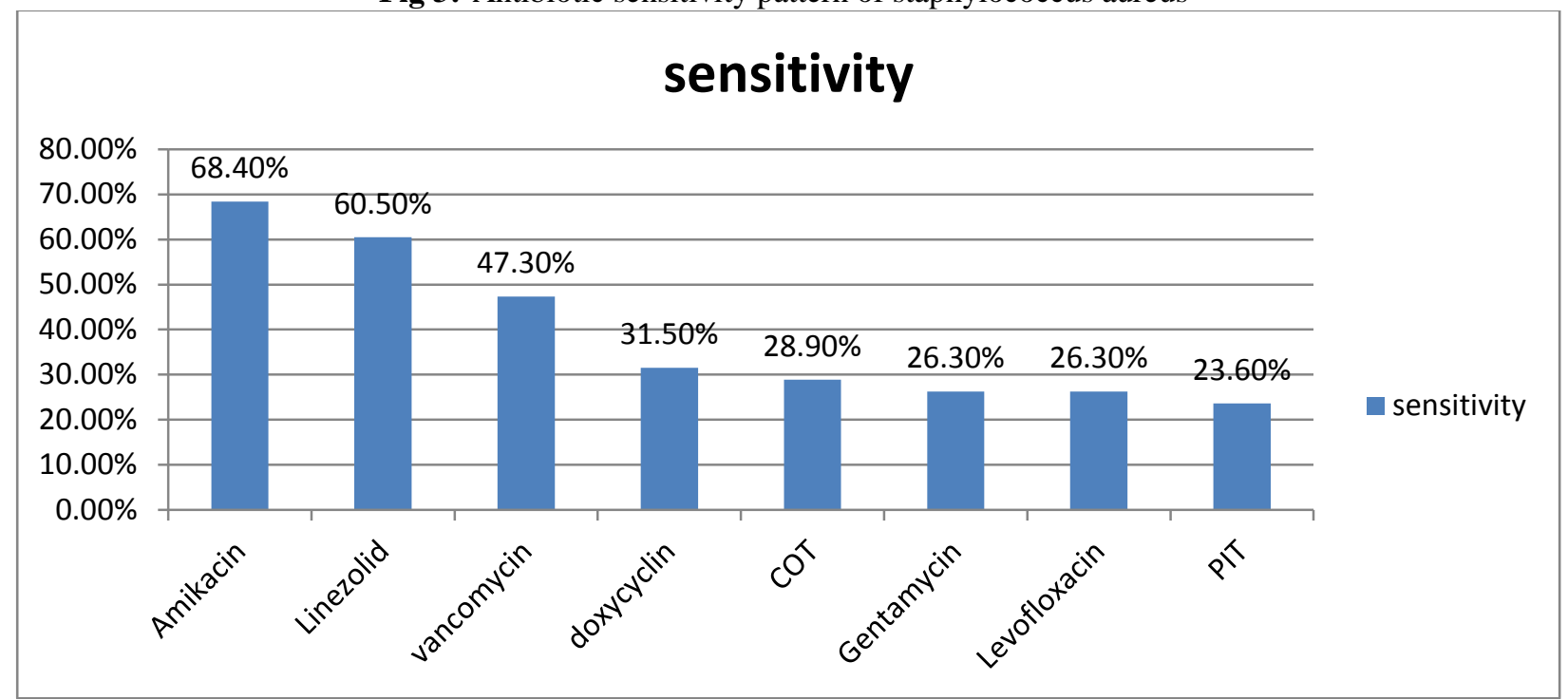

Fig 4:-Antibiotic sensitivity pattern of Gram Negative Bacilli PIT:pipperacillin and tazobactum, CIP: ciprofloxacin, CTR:ceftriaxone.

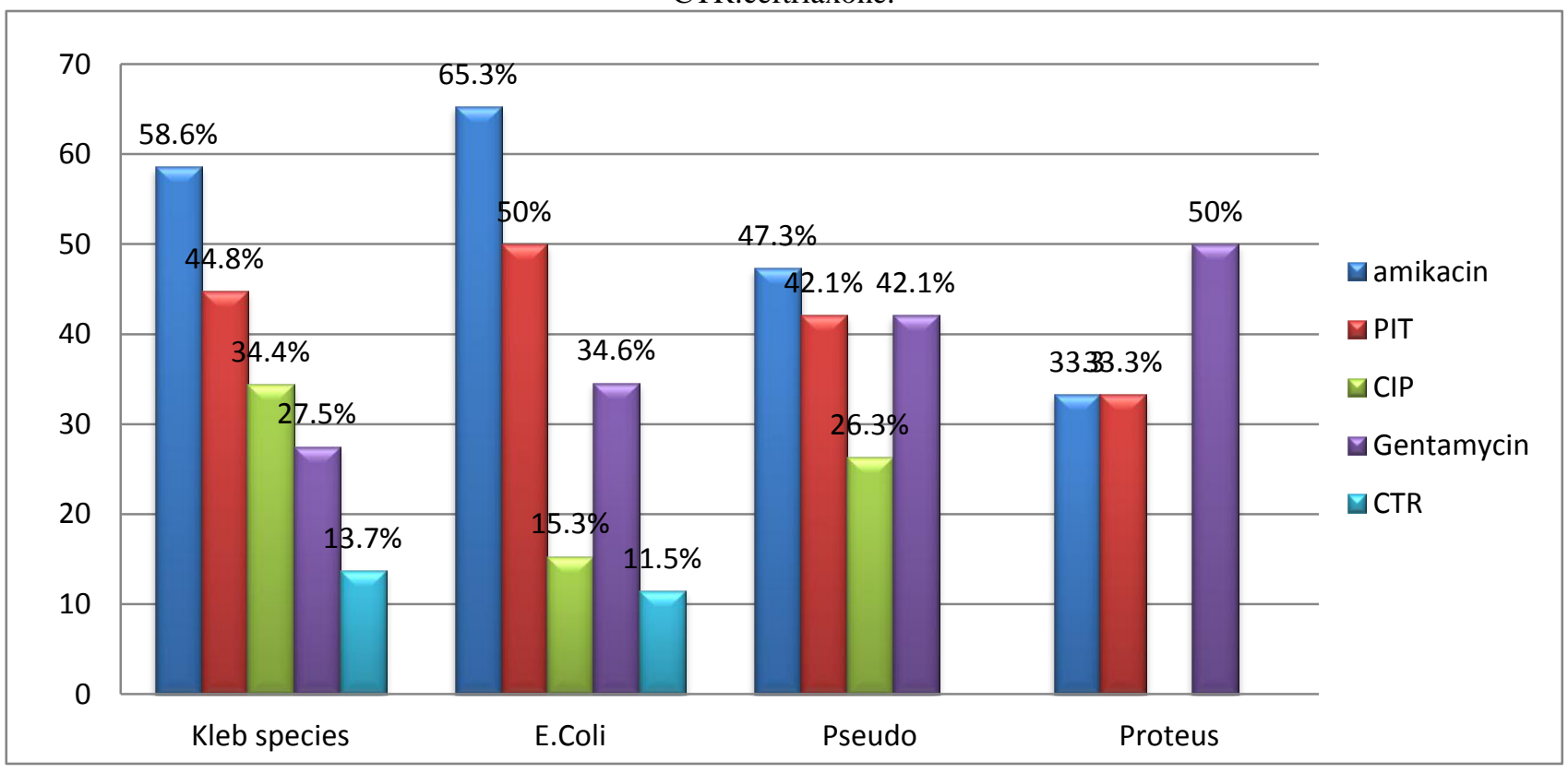




\section{References:-}

1. Agarwal SL (1972). Study of postoperative wound infection. Indian J. Surg. 34: 314-20.

2. Anguzu JR,Olila D (2007) Durg sensitivity patterns of bacterial isolates from septic post-operative wounds in a regional referral hospital in Uganda.Afr Health Sci 7:148-154.

3. Anvikar AR, Deshmukh AB, Karyakarte RP, Damle AS, Patwardhan NS, Malik AK, Bichile LK, Bajaj JK, Baradkar VP, Kulkarni JD, Sachdeo SM (1999). A one year prospective study of 3,280 surgical wounds. Indian J. Med. Microbiol. 17: 129-3.

4. Bastola R, Parajuli P, Neupane A, Paudel A (2017) Surgical Site infections: Distribution Studies of Sample, Outcome and AntimicrobialSusceptibility Testing. J Med MicrobDiagn 6: 252. doi:10.4172/21610703.1000252

5. CDC Healthcare-associated Infections (HAI) Types of Infections. Surgical Site Infection (SSI).

6. CLSI-Clinical and Laboratory Standards Institute 2016. Performance standards for antimicrobial susceptibility testing. Twenty-second informational supplement. Wayne, PA, USA.

7. Col LT. Hota P K. Single dose antibiotic prophylaxis in surgery: A prospective study. Indian Journal of Surgery 1997: 363- 367.

8. Gil-Egea MJ, Pi-Sunyer MT, Verdaguer A, Sanz F, Sitges-Serra A, Eleizegui LT. Surgical wound infections: prospective study of 4,468 clean wounds. Infect Control 1987; 8(7):277-80.

9. Green JW, Wenzel RP (1977). Postoperative wound infection. a controlled study of the increased duration of hospital stay and direct cost of hospitalization. Ann. Surg. 185: 264-268.

10. Horan TC, Gaynes RP, Martone WJ, Jarvis WR, Emori TG. CDC definitions of nosocomial surgical site infections, 1992: a modification of CDC definitions of surgical wound infections.Am J Infect Control., 1992; 20(5): 271-274. 6.

11. Kamat US, Fereirra AM, Kulakarni MS, Motaghare DD (2008). A prospective study of surgical site infection in a teaching hospital in Goa. Indian J. Surg., 70: 120-124.

12. Khaleid, M., Ibraheim, Z. 2010. Surgical Site Infections and Associated Risk Factors in Egyptian Orthopedic Patients, Amer. J. Sci., 6(7).

13. Lilani SP, Jangale N, Chowdhary A, Daver GB. Surgical site infection in clean and cleancontaminated cases. Indian J Med Microbiology. 2005; 23(4): 249-52. 5.

14. Mangram AJ, Horan TC, Pearson ML, Silver LC, Jarvis WR. Guideline for prevention of surgical site infection. Infect control hospepidemiol., 1999; 20: 247-78.

15. Manyahi J (2012) Bacteriological spectrum of post-operative wound infections and their antibiogram in a tertiary hospital. Daressalaam, Tanzania.

16. Mohamed Issa Ahmed1,2:Prevalence of Nosocomial Wound Infection Among Postoperative Patients and Antibiotics Patterns at Teaching Hospital in Sudan.

17. NazneenSiddiqui, SomnathNandkar, MuktaKhaparkuntikar and ArvindGaikwad. 2017. Surveillance of Postoperative Wound Infections Along with their Bacteriological Profile and Antibiotic Sensitivity Pattern at Government Cancer Hospital, Aurangabad, India. Int.J.Curr.Microbiol.App.Sci. 6(3): 595-600. doi: https://doi.org/10.20546/ijcmas.2017.603.069

18. Ramesh Rao, S.Sumathi, K.Anuradha, D.Venkatesh, S.Krishna. Bacteriology of postoperative wound infections. Int J Pharm Biomed Res. 2013;4:72-76.

19. Rao AS, Harsha M (1975). Postoperative wound infections. J Indian Med. Assoc. 64 :90-3

20. SandeepBhaskarrao Kokate1, Vaishali Rahangdale2, VyankateshJagannathKatkar Study of Bacteriological Profile of Post Operative Wound Infections in Surgical Wards in a Tertiary Care Hospital.

21. Shivaji Rao, M Harsha et al. Post operative wound infection. Journal of Indian Medical Association 1975; 64(4): 90-93.

22. Suchitra JB, Lakshmidevi N. Surgical site infections: Assessing risk factors, outcomes and antimicrobial sensitivity patterns.African Journal of Microbiology Research, 2009; 3(4):175-179.

23. Vikrant Negi1, Shekhar Pal2, Deepak Juyal3, Munesh Kumar Sharma4, Neelam Sharma5:Bacteriological Profile of Surgical Site Infections and Their Antibiogram: A Study From Resource Constrained Rural Setting of Uttarakhand State, India. 